Research Article

\title{
Formation and Penetration Capability of an Annular-Shaped Charge
}

\author{
Zhecheng Hu $(\mathbb{D}$, Zhijun Wang $\mathbb{D}$, Jianping Yin, and Jianya Yi \\ College of Mechatronic Engineering, North University of China, Taiyuan 030051, China \\ Correspondence should be addressed to Zhijun Wang; wzj@nuc.edu.cn
}

Received 3 December 2020; Revised 4 March 2021; Accepted 30 March 2021; Published 20 April 2021

Academic Editor: Jian G. Zhou

Copyright (C) 2021 Zhecheng Hu et al. This is an open access article distributed under the Creative Commons Attribution License, which permits unrestricted use, distribution, and reproduction in any medium, provided the original work is properly cited.

\begin{abstract}
Shaped charges are widely used in the field of national defense because of their high energy density and strong directivity; however, one of their limitations is that the penetration diameter is small. Compared with a traditional shaped charge, an annular-shaped charge can create a larger penetration aperture at the target, thereby causing more damage to underwater targets. To enhance the damage effect of a shaped charge on an underwater structure, we designed an annular-shaped charge structure. To end this, we first established a velocity calculation model of the liner and analyzed its formation process. The hydrocode software Autodyn was used to simulate the jet formation process. Second, two parameters of the annular liner height and thickness of the bottom and their effect on the annular jet formation were analyzed. Finally, an experiment was conducted to validate the penetration capability of this charge. The experimental results indicate that the annular-shaped charge can penetrate a typical underwater structure and form a large penetration aperture with a diameter of $420 \mathrm{~mm}$, which is 1.4 times the charge diameter. Furthermore, the numerical results show good agreement with the experimental data; only a $1.67 \%$ deviation was observed.
\end{abstract}

\section{Introduction}

Naval structures are severely damaged by shock waves and metal jets associated with underwater explosions $[1,2]$. Therefore, shaped charges are widely used in national defense such as in antiships. A shaped charge [3-12] is composed of two major components: charge and liner. After detonation, under the action of detonation waves and detonation products, the liner deforms and collides on the axis, finally forming a metal jet with high energy and high speed. Many research studies have investigated the effect of shaped charges against underwater targets. For example, Zhang et al. [13] established Smoothed Particle Hydrodynamics (SPH) models for single- and double-cylindrical shells (single hull and double hull) and studied the damage caused using Autodyn (Ansys). Kumar et al. [14] studied four different cases of air backup, water backup, partial water backup, and free flood water backup through explosion bulge test (EBT) experiments, and they compared the response of a double hull to the proximity explosion with air and water backup using a finite element (FE) model. Zhang et al. [15] investigated the effect on the damage response of a plate to an underwater explosion for three different shapes of a charge liner: conical, hemispherical, and spherical.

With the developments in technology, many new types of shaped charges that have higher penetration performances have been designed; these include an annular-shaped charge. Compared with a traditional shaped charge, an annular-shaped charge can create a larger hole in the target. The penetration diameter of an annular jet can reach one charge diameter (1D). In 1978, Leidel [16] designed an annular-shaped charge structure in his $\mathrm{PhD}$ thesis. He added a steel cylinder in the shaped charge, and the liner formed an annular jet. Chick et al. [17] investigated a cookie-cutter explosive based on the geometry of linear-shaped charges. Their results suggested that the jet formed by this structure was unstable and could not effectively cut a circle from the target. Next, they designed a new liner structure and simulated the penetration process using numerical simulation software. The results of the numerical simulation indicated that the liner created a hollow explosive-formed projectile (EFP) and cut a hole of 0.75 charge diameter (D) in the target plate located at a 
distance of 3D. Konig and Monster [18] designed a ring-shaped liner with a variable liner thickness. The outer wall of the liner was designed forward, and the thickness was lower than that of the inner wall; this helped ensure that the outer wall would turn over earlier compared to the inner wall to form the EFP head. Through simulations and experiments, he indicated that the diameter of the EFP is equal to the charge diameter, and the length is approximately $1 / 3$ of the charge diameter. Wang et al. [19] proposed the equal impulse method for the structural design of an annular-shaped charge where impulses acting on the corresponding microelements of the inner and outer liners are equal to ensure that the annular jet is not skewed. Meister and Haller [20] designed a symmetrical linear structure with a "sickle-shaped" section, and they studied the formation process when aluminum, iron, lead, and tantalum were used as the liner materials. Further, they found that all these materials formed an EFP and created a hole diameter larger than D on the target plate located at a distance of 2.5D. Richard et al. [21] introduced some annular-shaped charge structures studied by the U.S. Army Armament Research, Development and Engineering Center. Their numerical simulation results indicated that the circular EFP formed by these structures could cut holes about the size of a person in a brick or reinforced concrete wall. $\mathrm{Li}$ et al. [22] designed a double-ring EFP (DEFP)-shaped charge structure. Their numerical simulation results indicated that their structure could form a two-layer separated circular EFP, with both creating at least $1.7 \mathrm{D}$ openings on the concrete wall located at a distance of 1D. Xu et al. $[23,24]$ designed a borecenter annular-shaped charge to improve the penetration diameter and depth for hard targets, and they conducted $X$-ray experiments to validate the reliability of their numerical results. Their results showed that the jet can form a hole of $0.92 \mathrm{D}$ on a steel plate, with a penetration depth of $0.56 \mathrm{D}$. They then studied the influence of the liner material on the jet penetration of steel targets and found that a molybdenum liner achieved the greatest penetration depth. However, there are few studies on the application of annular-shaped charges to underwater structures.

In this study, we designed a type of annular-shaped charge. The liner of this charge is composed of an eccentric subhemisphere liner and an annular liner. Therefore, this charge can create two penetrators, the jet in the middle, and the annular jet on the outside. First, we analyzed the formation process using theoretical analysis and numerical simulation. Then, the effect of the structural parameters of the annular liner on the annular jet formation was studied. Finally, an experiment involving the annular-shaped charge penetrating a typical underwater target was conducted. The penetration ability of this annular-shaped charge was verified by comparing the experimental results with the simulation data. Compared with the traditional-shaped charge, the proposed annular-shaped charge cannot only penetrate but also cause a larger opening diameter on the underwater targets, thereby improving its damage effect.

\section{Theory}

The structure of the annular-shaped charge is shown in Figure 1. The charge is divided into outer and central parts that are separated by a wave shaper; the initiation mode is a combination of central point initiation and ring initiation. The wave shaper has two functions: changing the shape of the detonation wave or blocking the propagation of the detonation wave $[25,26]$. In this study, the wave shaper is filled to avoid interference from the internal and external detonation waves as far as possible. After its detonation, the detonation wave acts on the annular liner and moves away from the charge axis. In this process, the diameter of the annular jet increases continuously and finally exceeds 1D. The formation process of the annular jet is shown in Figure 2.

2.1. Velocity Model of the Annular Jet. Let $A$ denote a small element from the annular liner, as shown in Figure 3. After the detonation, the detonation wave travels forward at a speed of $D$. When the detonation wave reaches $A$, it adds a collapse velocity $V_{0}$ to this element. There is an angle $\delta$ between $V_{0}$ and the normal direction of point $\mathrm{A}(n)$; this angle is called a projection angle. It can be considered that this element is affected by two parts of explosives: the explosive $C p$ in the $X$ direction, which acts on element $A$ like the explosive driving a metal plate, and explosive $C c$ in the $Y$ direction, which acts on the A-like explosive, driving the cylinder inward. Next, VA can be divided into two components: $V_{A X}$ and $V_{A Y}$ along the $X$ - and $Y$-axes, respectively. The value of $V_{A X}$ determines the stretching degree of the liner, and the value of $V_{A Y}$ determines the degree of the outward expansion of the liner.

According to the Gurney formula,

$$
V_{A X}=\sqrt{2 E}\left\{\frac{1}{3}\left[\left(\frac{2 M}{M_{C p}}\right)^{2}+\frac{5 M}{M_{C p}}+1\right]\right\}^{-(1 / 2)}
$$

where $M$ denotes the mass of element $A, M_{C p}$ denotes the mass of the explosive $C p$, and $\sqrt{2 E}$ represents the Gurney constant of the explosive:

$$
V_{A Y}=\sqrt{2 E}\left[\left(\frac{R_{e}^{2}-R_{i}^{2}}{R_{X}^{2}-R_{i}^{2}}\right) \frac{M}{M_{C c}}+\frac{1}{6}\right]^{-(1 / 2)}
$$

where $M_{C c}$ denotes the mass of the explosive $C c$ and $R_{e}$ and $R_{i}$ represent the inner radius and outer radius of explosive $C c$, respectively. Further, $R_{x}$ represents the radius of the rigid surface in the explosive; on this surface, the velocity of the detonation product is zero, and we have

$$
\begin{aligned}
& R_{X}^{3}+3 R_{X}\left[\left(R_{e}+R_{i}\right) \frac{\rho_{0}}{\rho_{c j}}\left(\frac{M}{M_{C c}} R_{e}+\frac{M_{t}}{M_{C c}} R_{i}\right)+R_{e} R_{i}\right] \\
& \quad-3\left(R_{e}+R_{i}\right) R_{e} R_{i}\left[\frac{2}{3}+\frac{\rho_{0}}{\rho_{c j}}\left(\frac{M}{M_{C c}}+\frac{M_{t}}{M_{C c}}\right)\right]=0, \\
& \rho_{c j}=\frac{k+1}{k} \rho_{0}, \quad k \approx 3,
\end{aligned}
$$

where $\rho_{0}$ represents the density of the explosive. 


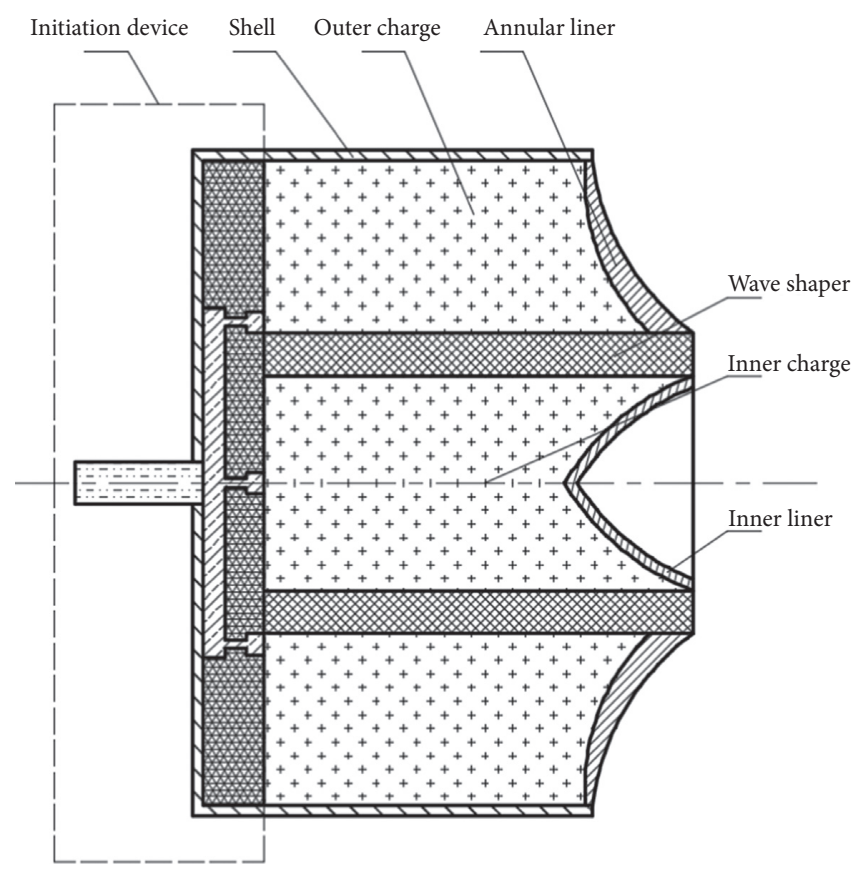

FIgURE 1: Schematic of the shaped charge structure.

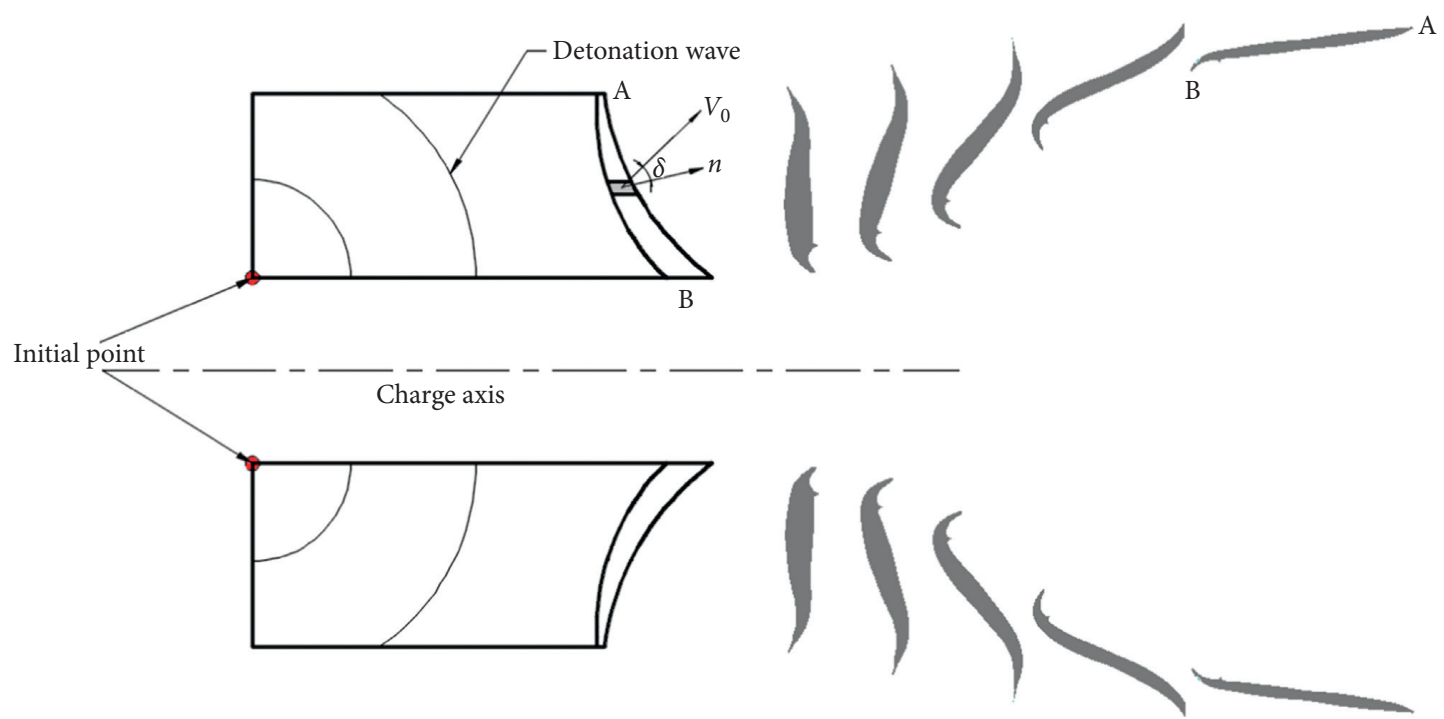

FIgURE 2: Formation process of the annular jet.

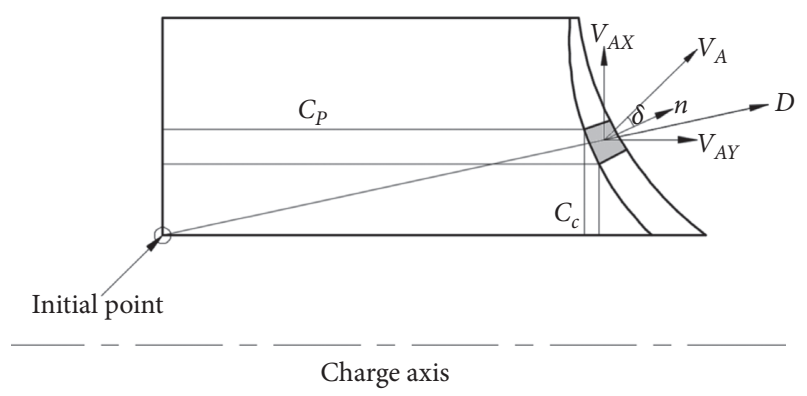

Figure 3: Effect of explosive on the element of the annular liner.
2.2. Velocity Model of JPC. Let B, BC, and O denote a small element on the eccentric subhemisphere liner, the profile curve of the liner, and the detonation point, respectively. After some time, $B$ moves to $B^{\prime}$ under the pressure of the detonation wave (Figure 4). The velocity of the detonation wave sweeping through point B can be expressed as

$$
U=\frac{D}{\cos i},
$$

where $D$ denotes the velocity of the detonation wave and $i$ represents the angle between the normal line of the wavefront and the tangent of the liner at point $B$. 
The projection angle $\delta$ can be expressed as

$$
\sin \delta=\frac{V_{B}}{2 U}
$$

where $V_{B}$ denotes the crushing velocity of point $\mathrm{B}$, which can be decomposed into two components: $v_{1}$ along the charge axis direction and $v_{2}$ along the tangent direction of the liner surface:

$$
\overrightarrow{V_{B}}=\overrightarrow{v_{1}}+\overrightarrow{v_{2}}
$$

Based on the crushing process of the liner in the moving coordinate system with a velocity of $v_{1}$, we can see that the liner material flows at a velocity of $v_{2}$. This scenario seems like a steady stream hitting a rigid wall. According to ideal incompressible fluid mechanics, it is divided into two streams of fluids with the same speed, and it then forms the jet and slug, respectively. Therefore, the velocity of the jet and pestle can be expressed as

$$
\begin{aligned}
& V_{j}=v_{1}+v_{2}, \\
& V_{s}=v_{1}-v_{2} .
\end{aligned}
$$

Next, through the geometric relationship indicated in Figure 4, the velocity of jet $V_{j}$ and slug $V_{s}$ can be obtained as

$$
\begin{aligned}
& V_{j}=v_{1}+v_{2}=V_{B} \csc \frac{\beta}{2} \cos \left[\alpha+\delta-\frac{\beta}{2}\right], \\
& V_{s}=v_{1}-v_{2}=V_{B} \sec \frac{\beta}{2} \sin \left[\alpha+\delta-\frac{\beta}{2}\right],
\end{aligned}
$$

where $\beta$ denotes the crushing angle. $V_{B}$ can be obtained using equations (1) and (2).

According to the conservation of mass and momentum,

$$
\begin{aligned}
& \frac{d m_{j}}{d m}=\sin ^{2} \frac{\beta}{2}, \\
& \frac{d m_{s}}{d m}=\cos ^{2} \frac{\beta}{2},
\end{aligned}
$$

where $d m$ denotes the mass of element $B$ and $d m_{j}$ and $d m_{s}$ represent the mass of the jet and the slug formed by element $B$ after collision, respectively.

\section{Numerical Simulation}

In this study, we performed numerical simulations to investigate the formation process of the shaped charge and examine the effect of structural parameters on the formation of annular jets. Autodyn-2D was used to perform the simulations; the simulation model and the structural parameters of shaped charge are shown in Figure 5. Because this shaped charge structure has a symmetry axis, only $1 / 2$ of the model was established. The calculation model adopts the $(\mathrm{cm}, \mathrm{g}, \mu \mathrm{s})$ unit system, the simulation air area is $100 \mathrm{~cm} \times 20 \mathrm{~cm}$, and the size of the mesh is set as $1 \mathrm{~mm} \times 1 \mathrm{~mm}$ to preserve reasonable accuracy and computational costs. The initial condition was applied to the air area, and the initial specific internal energy of the air was
$2.068 \times 10^{-3} \mathrm{~cm}^{2} / \mu \mathrm{s}^{2}$. The "flow out (Euler)" boundary is applied to the air area, which implies that the detonation products will not affect the formation of EFPs after flowing out of the air area.

The Euler algorithm is adopted for the explosive, wave shaper, and inner liner because of the large deformation. The annular liner will form an annular jet that is more likely to be an explosively formed projectile (EFP), and a Lagrange algorithm is therefore adopted for it. The model is established using the "part" function of Autodyn, and the entire modeling process is performed in Autodyn. All materials were obtained from the Autodyn material library [27]. To observe the velocity variation of the annular liner during the formation process, we plotted seven moving gauges on the annular liner.

3.1. Material Models. The equation of state (EOS) of air is ideal gas, which can be used in many applications involving the motion of gases. This equation can be derived from the laws of Boyle and Gay-Lussac, and it is expressed as

$$
p=(\gamma-1) \rho e .
$$

In this equation, only the value of the adiabatic exponent $\gamma$ must be supplied. For air, its density $\rho=0.001225 \mathrm{~g} / \mathrm{cm}^{3}$ and $\gamma=1.4$.

The polynomial equation of state is used to describe water. For the polynomial EOS, when water is compressed, $\mu>0$, and the state equation is expressed as

$$
p=A_{1} \mu+A_{2} \mu^{2}+A_{3} \mu^{3}+\left(B_{0}+B_{1} \mu\right) \rho_{0} e .
$$

Furthermore, when water expands, $\mu<0$, and the state equation expression is

$$
\begin{aligned}
& p=T_{1} \mu+T_{2} \mu^{2}+T_{3} \mu^{3}+B_{0} \rho_{0} e, \\
& \mu=\frac{\rho}{\rho_{0}}-1,
\end{aligned}
$$

where $\mu$ denotes the compression ratio, $\rho_{0}$ denotes the initial density of water at room temperature, and $e$ represents the internal energy per unit mass.

When water is neither compressed nor expanded, $\mu=0$, and equation (11) changes to

$$
p=B_{0} \rho_{0} e
$$

The specific parameters of water are listed in Table 1.

The explosive is made from composition B (COMP B), which consists of $40 \%$ TNT and $60 \%$ RDX, and its density $\rho_{B}=1.71 \mathrm{~g} / \mathrm{cm}^{3}$, detonation velocity $V_{D}=7980 \mathrm{~m} / \mathrm{s}$, and detonation pressure $P_{c j}=34.2 \mathrm{GPa}$. The equation of state is the JWL equation:

$$
P_{E}=A_{1}\left(1-\frac{\omega}{R_{1} V}\right) e^{-R_{1} V}+B_{1}\left(1-\frac{\omega}{R_{2} V}\right) e^{-R_{2} V}+\frac{\omega E_{0}}{V},
$$

where $P_{E}$ denotes the pressure, $V=1 / \rho_{B}$ denotes the specific volume, $E_{0}$ denotes the specific internal energy per unit 


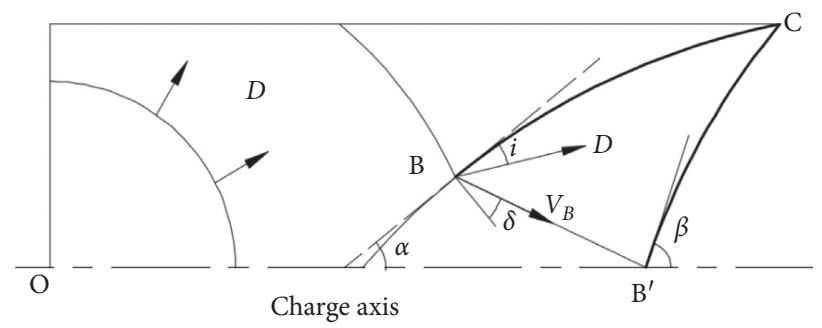

FIgURE 4: Collapse of the eccentric subhemisphere liner.

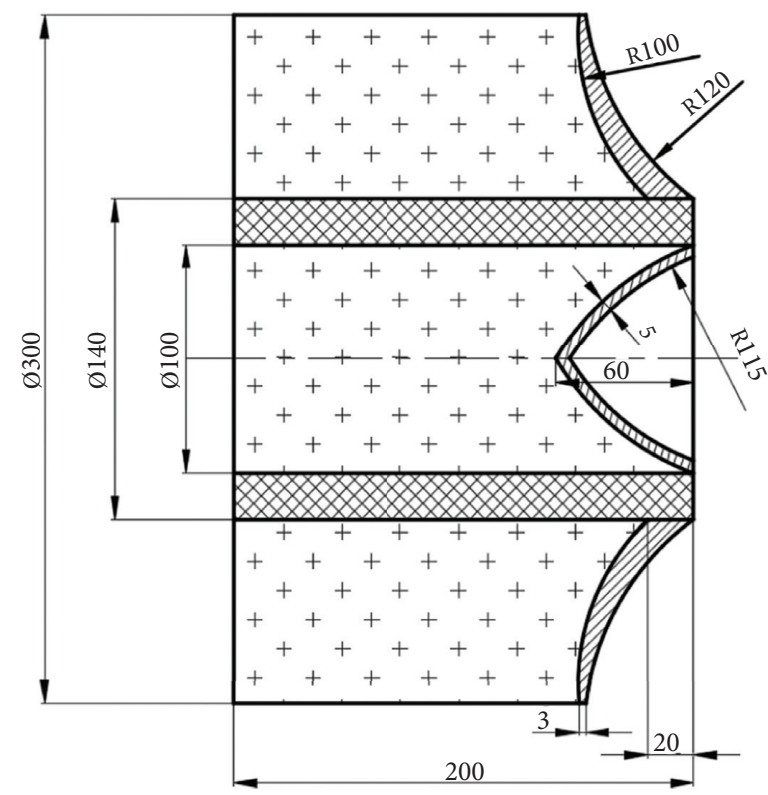

(a)
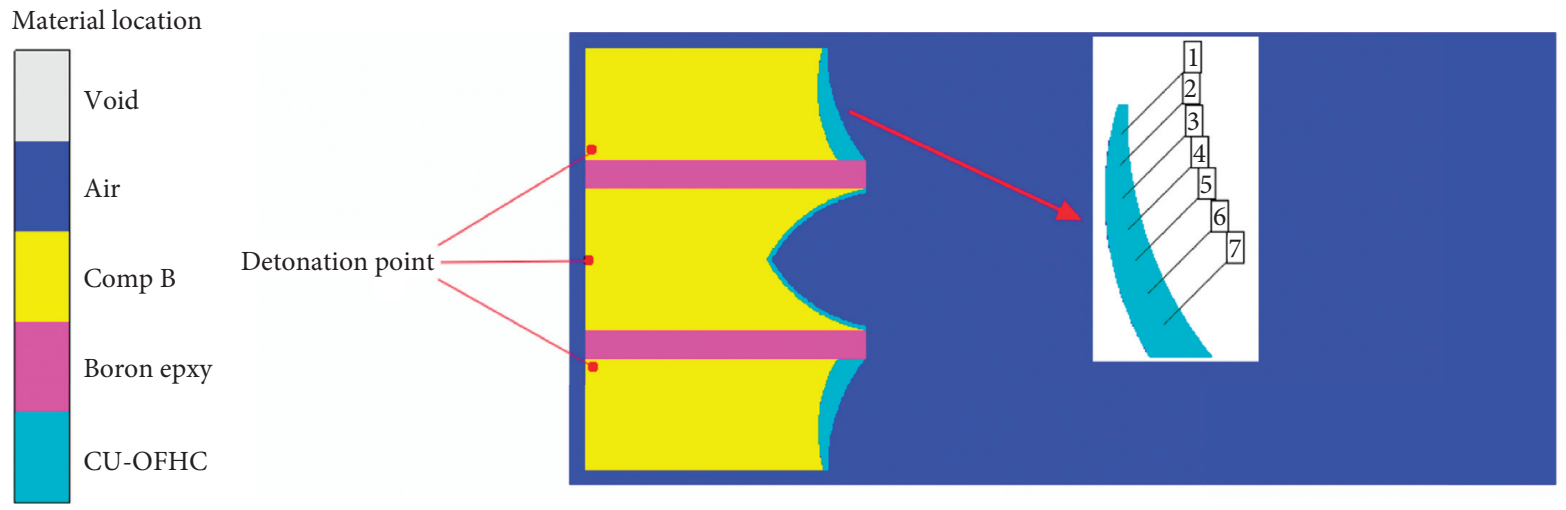

(b)

FIGURE 5: Modeling of the shaped charge. (a) Geometric modeling of the shaped charge. (b) Numerical model of the formation process of JPC and annular jet.

Table 1: Polynomial equation of water.

\begin{tabular}{lccccccc}
\hline Material & $A_{1}(\mathrm{GPa})$ & $A_{2}(\mathrm{GPa})$ & $A_{3}(\mathrm{GPa})$ & $B_{0}$ & $B_{1}$ & $T_{1}(\mathrm{GPa})$ & $T_{2}(\mathrm{GPa})$ \\
\hline Water & 2.2 & 9.54 & 14.57 & 0.28 & 0.28 & 2.2 & 0 \\
\hline
\end{tabular}


mass, and $A_{1}, B_{1}, R_{1}, R_{2}$, and $\omega$ are material constants. The JWL model parameters of the COMP B explosive are listed in Table 2.

The liner was fabricated from anaerobic copper (CU-OFHC) with a density $\rho=8.93 \mathrm{~g} / \mathrm{cm}^{3}$. The EOS of copper is based on a shock model. The shock EOS describes the relationship between the pressure and internal energy at a point outside the Hugoniot curve; for the point on the curve,

$$
P=P_{H}+\Gamma \rho\left(E-E_{H}\right),
$$

where $\Gamma \rho=\Gamma_{0} \rho_{0}=$ constant, $\rho$ denotes the density, and $\Gamma$ denotes the Grüneisen coefficient that is often approximated as 2. Furthermore, $P_{H}$ and $E_{H}$ represent the Hugoniot pressure and energy, respectively.

The strength mode of anaerobic copper is JohnsonCook, which is divided into three items that reflect the strain effect, strain rate effect, and thermal softening effect of materials:

$$
\begin{aligned}
\sigma_{y} & =\left(A+B \varepsilon_{p}^{n}\right)\left(1+C \log \varepsilon_{p}^{*}\right)\left(1-T_{H}^{m}\right), \\
T_{H} & =\frac{\left(T-T_{r}\right)}{\left(T_{m}-T\right)},
\end{aligned}
$$

where $\sigma_{y}$ denotes the dynamic yield stress, $\varepsilon_{p}$ denotes the effective plastic strain, $\varepsilon_{p}^{*}$ denotes the normalized effective plastic strain rate, $A$ denotes the static yield stress, $B$ represents the hardening constant, $C$ represents the strain rate constant, $n$ represents the hardening exponent, and $m$ represents the thermal softening exponent. Further, $T_{H}$ denotes the relative temperature, and $T_{m}$ and $T_{r}$ represent the melting temperature and room temperature, respectively. $G$ denotes shear modulus.

The target is composed of steel with a density $\rho=7.896 \mathrm{~g} / \mathrm{cm}^{3}$; its EOS and strength mode are the same as those of the CU-OFHC. When calculating the process of annular jet penetration into the target, the erosion model "geometric strain" is added to the material steel.

Geometric strain is a measure of the distortion of an element, and it is calculated from the principal strain components as

$$
\begin{aligned}
\varepsilon_{\text {eff }}= & \frac{2}{3}\left[\mid\left(\varepsilon_{1}{ }^{2}+\varepsilon_{2}{ }^{2}+\varepsilon_{3}{ }^{2}\right)-\left(\varepsilon_{1} \varepsilon_{2}+\varepsilon_{2} \varepsilon_{3}+\varepsilon_{3} \varepsilon_{1}\right)\right. \\
& \left.+3\left(\varepsilon_{12}{ }^{2}+\varepsilon_{23}{ }^{2}+\varepsilon_{31}{ }^{2}\right) \mid\right]^{1 / 2} .
\end{aligned}
$$

The typical values range from $0.5-2.0$. In the simulation, we set this value to 1.0. The parameters of the metal materials are listed in Table 3.

The wave shaper is fabricated using boron epoxy resin (BORON EPXY) that has a density $\rho=1.985 \mathrm{~g} / \mathrm{cm}^{3}$; its EOS is puff. This EOS was constructed to cover the behavior of materials from cold-shocked regions to hot, highly expanded regions. The formulation is given as follows.

When $\mu \geq 0$,

$$
p_{1}=\left(A_{1} \mu+A_{2} \mu^{2}+A_{3} \mu^{3}\right)\left(\frac{1-\Gamma \mu}{2}\right)+\Gamma \rho e .
$$

When $\mu<0$ and $e<e_{s}$,

$$
p_{2}=\left(T_{1} \mu+T_{2} \mu^{2}\right)\left(\frac{1-\Gamma \mu}{2}\right)+\Gamma \rho e .
$$

When $\mu<0$ and $e \geq e_{s}$,

$$
p_{3}=\rho\left[H+\left(\Gamma_{0}-H\right) \eta^{1 / 2}\right]\left[e-e_{s}\left\{1-\exp \left(\frac{N(\eta-1)}{\eta^{2}}\right)\right\}\right] \text {, }
$$

where $\Gamma_{0}$ represents the Grüneisen Gamma, $H$ represents an expansion coefficient, $e_{s}$ denotes the sublimation energy, and $A_{1}, A_{2}, A_{3}, T_{1}$, and $T_{2}$ are constants. Table 4 lists the parameters of the puff EOS.

3.2. Mesh Sensitivity. Mesh sizes affect the efficiency and accuracy of numerical simulations. To obtain the proper mesh size, we designed three groups of shaped charge structure formation simulations under different grid sizes. Owing to the large simulation model and considering the calculation time, the selected mesh sizes were $0.5,1$, and $1.5 \mathrm{~mm}$. Figure 6 shows the variation in the tip velocity of the JPC and annular jet over time for the different mesh sizes. For the annular jet, the three velocity curves are very close. For the velocity profiles of JPC, the curve of $0.4 \mathrm{~mm}$ mesh size is close to the curve of the $1 \mathrm{~mm}$ mesh size; however, the curve of the $1.5 \mathrm{~mm}$ mesh size shows some deviation. Further, Table 5 lists the main parameters of the annular jet and JPC during their formation process, and these parameters are the maximum tip velocity of annular jet $\left(V_{t A}\right)$, diameter $\left(D_{A}\right)$, and length $\left(L_{A}\right)$ of the annular jet after its formation and the maximum tip velocity $\left(V_{t J}\right)$ of JPC and its length $\left(L_{J}\right)$ at $100 \mu \mathrm{s}$. Table 5 indicates that the deviation of $V_{t A}, D_{A}, L_{A}, V_{t}$, and $L_{J}$ between the square mesh size of $0.5 \mathrm{~mm}$ and $1.0 \mathrm{~mm}$ is $0.4 \%, 1.1 \%, 0.2 \%, 1.4 \%$, and $2.8 \%$, respectively. Further, these values between the square mesh sizes of $1.0 \mathrm{~mm}$ and $1.5 \mathrm{~mm}$ are $2.5 \%, 5.6 \%, 1.5 \%, 7.6 \%$, and $12.1 \%$. The results of this analysis indicate that the calculation accuracy of the $0.5 \mathrm{~mm}$ mesh size and the $1.0 \mathrm{~mm}$ mesh size is close. However, the time consumption of the $0.5 \mathrm{~mm}$ mesh size is several times that of the $1.0 \mathrm{~mm}$ mesh size. Thus, considering reasonable accuracy and time consumption, the size of the mesh is set to $1.0 \mathrm{~mm} \times 1.0 \mathrm{~mm}$.

3.3. Formation Process of JPC and Annular Jet. Figure 7 shows the formation process of the annular jet and the JPC. For the convenience of viewing, we only consider the cross section of the jet. The velocity profile of each gauge is shown in Figure 8. During the formation process, the annular jet tends to expand outward toward the charge axis. At $150 \mu \mathrm{s}$, the tip velocities of the JPC and annular jet are $6288 \mathrm{~m} / \mathrm{s}$ and $1661 \mathrm{~m} / \mathrm{s}$, respectively. Further, Figure 8 indicates that, after the detonation, the speed of the top of the liner is initially smaller than that of the bottom of the liner; 
TABLE 2: JWL model parameters of composition B explosive.

\begin{tabular}{lcccccc}
\hline Material & $E_{0}(\mathrm{GPa})$ & $A_{1}(\mathrm{GPa})$ & $B_{1}(\mathrm{GPa})$ & $R_{1}$ & $R_{2}$ & $\omega$ \\
\hline COMP B & 8.50 & 524.2 & 7.678 & 4.20 & 1.10 & 0.34 \\
\hline
\end{tabular}

TABle 3: Parameters of metal materials.

\begin{tabular}{lcccccccc}
\hline Material & $\Gamma$ & $G(\mathrm{GPa})$ & $A(\mathrm{GPa})$ & $B(\mathrm{GPa})$ & $N$ & $c$ & $m$ & $T_{m}(\mathrm{~K})$ \\
\hline CU-OFHC & 2 & 46 & 0.09 & 0.292 & 0.31 & 0.025 & 1.09 & 1356 \\
Steel & 2.17 & 81.8 & 0.35 & 0.275 & 0.36 & 0.022 & 1.0 & 1811 \\
\hline
\end{tabular}

TABle 4: Puff equation of the wave shaper.

\begin{tabular}{lcccccccc}
\hline Material & $A_{1}(\mathrm{GPa})$ & $A_{2}(\mathrm{GPa})$ & $A_{3}(\mathrm{GPa})$ & $\Gamma_{0}$ & $H$ & $e_{s}(\mathrm{Terg} / \mathrm{g})$ & $T_{1}(\mathrm{Terg} / \mathrm{g})$ & $T_{2}(\mathrm{Terg} / \mathrm{g})$ \\
\hline Boron EPXY & 17.89 & 201.2 & -6.053 & 1.72 & 0.25 & 0.0598 & 0 & 0 \\
\hline
\end{tabular}

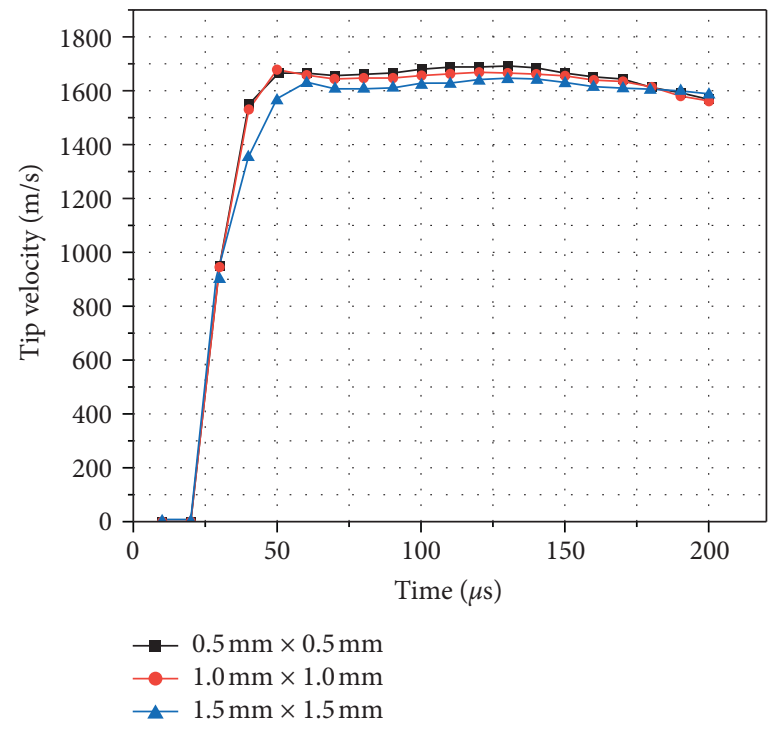

(a)

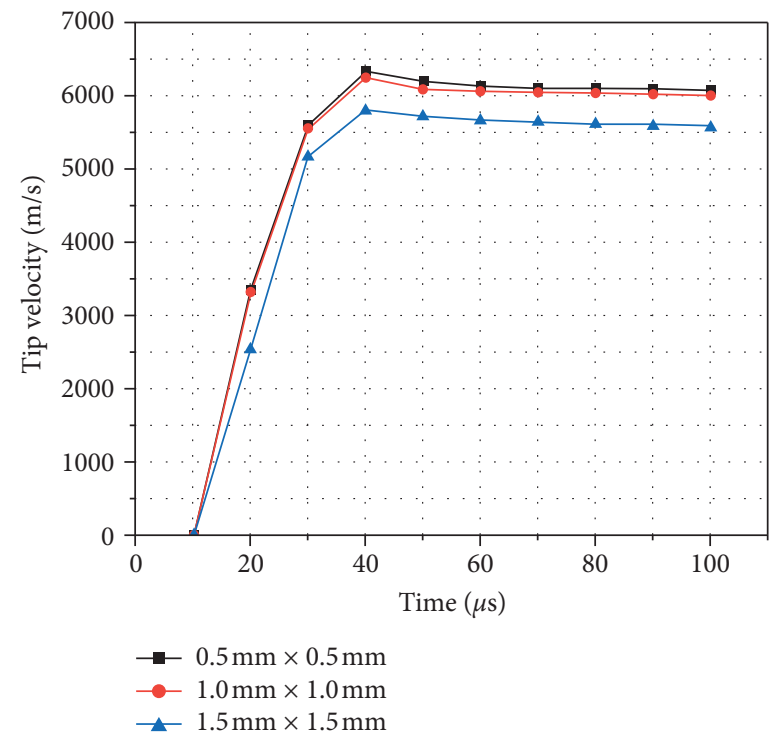

(b)

FIGURE 6: Variation of tip velocity over time at different mesh sizes. (a) Tip velocity of the annular jet. (b) Tip velocity of JPC.

TABLE 5: Values of parameters of the annular jet with different values of $H$.

\begin{tabular}{lccccc}
\hline & \multicolumn{3}{c}{ Annular jet } & \multicolumn{2}{c}{ JPC } \\
$\begin{array}{l}\text { Mesh } \\
\text { sizes }(\mathrm{mm})\end{array}$ & $V_{t A}(\mathrm{~m} / \mathrm{s})$ & $D_{A}(\mathrm{~mm})$ & $L_{A}(\mathrm{~mm})$ & $V_{t J}(\mathrm{~m} / \mathrm{s})$ & $L_{J}(\mathrm{~mm})$ \\
\hline $0.5 \times 0.5$ & 1695 & 356 & 82.7 & 6345 & 403.3 \\
$1.0 \times 1.0$ & 1688 & 360 & 82.9 & 6256 & 392.4 \\
$1.5 \times 1.5$ & 1645 & 380 & 84.1 & 5812 & 350.2 \\
\hline
\end{tabular}

however, after approximately $220 \mu$ s, this scenario changes. According to the previous analysis, the element close to the charge axis has a larger amount of explosive, which pushes it to move along the $X$ direction. However, because of the larger mass, it takes some time for the bottom of the liner to improve its speed. The $Y$ velocity of the annular liner increases along the $Y$ direction, and the velocity difference continues to increase. The results of the above analysis indicate that, during the formation process, the annular jet not only expands outward but also keeps turning over; further, after $220 \mu \mathrm{s}$, its penetration capability reduces sharply.

\subsection{Influence of Liner Structure Parameters on the Annular Jet} Formation. Before the analysis, a few explanations must be provided. In this study, we assume that the side of the charge near the initiation device is the top of charge, and the other side is the bottom of the charge; this is also the case for the liner. The key point of this study is the design of an annular liner.

To improve the penetration capability of the annular jet, the influence of the structural parameters of the annular 

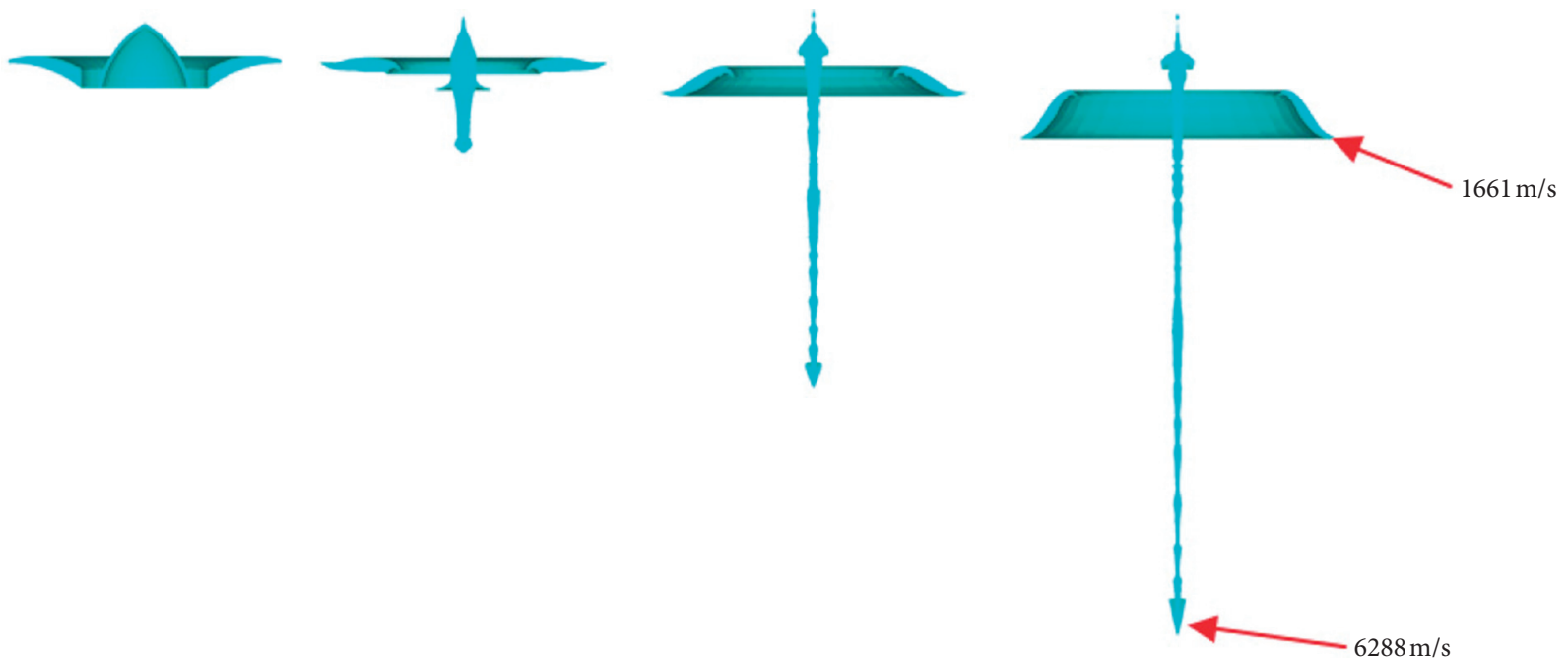

(a)

(b)

(c)

(d)

Figure 7: Formation process of JPC and annular jet. (a) $t=0 \mu \mathrm{s}$. (b) $t=50 \mu \mathrm{s}$. (c) $t=100 \mu \mathrm{s}$. (d) $t=150 \mu \mathrm{s}$.

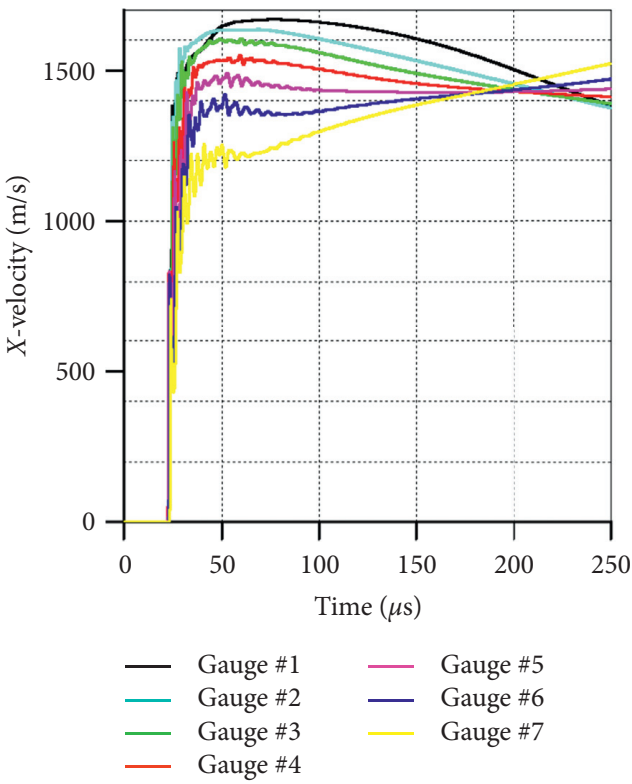

(a)

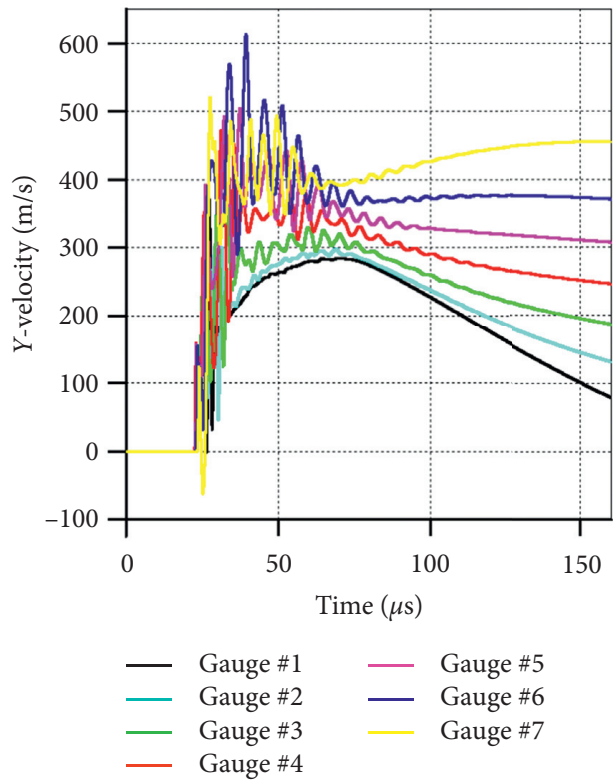

(b)

FIgURE 8: Velocity profiles of gauges. (a) $X$ velocity of each gauge. (b) $Y$ velocity of each gauge.

liner on the jet formation needs to be investigated. Two factors that have the greatest influence on jet formation were studied through numerical simulation: the height of the liner $H$ and the wall thickness of the liner. These parameters are illustrated in Figure 9.

We first investigated the effect of parameter $H$ on the formation of the annular jet, and five cases of $H$ were considered: $30,40,50,60$, and $70 \mathrm{~mm}$. The other parameters of the liner are fixed. We consider four parameters of the annular jet that influence its penetration capability: two components of the velocity of the jet head $\left(V_{t X}\right.$ and $\left.V_{t Y}\right)$, the length of the jet $(L)$, and the radius of the jet head $\left(r_{h}\right)$. The influence of $H$ on these parameters is illustrated in Figure 10. Furthermore, Figure 11 shows the form of the annular jet at $200 \mu$ s, and only half of the annular jet is shown for the sake of observation.

Figures 10 and 11 indicate that $H$ considerably affects $r_{h}$, and with an increase in $H$, the value of $r_{h}$ increases linearly. Further, with an increase in $H$, the value of $L$ increases, but it is not too large; the value of $V_{t X}$ drops slightly; and the value of $V_{t Y}$ increases considerably. The parameters $L$ and $r_{h}$ affect the penetration depth and penetration diameter, respectively. An increase in these two values is conducive to improving the penetration capability of the annular jet. 


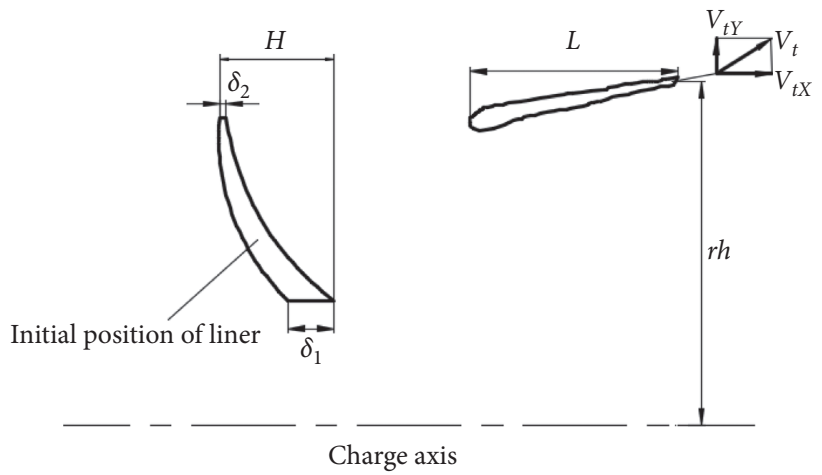

Figure 9: Schematic of the parameters of the annular jet.

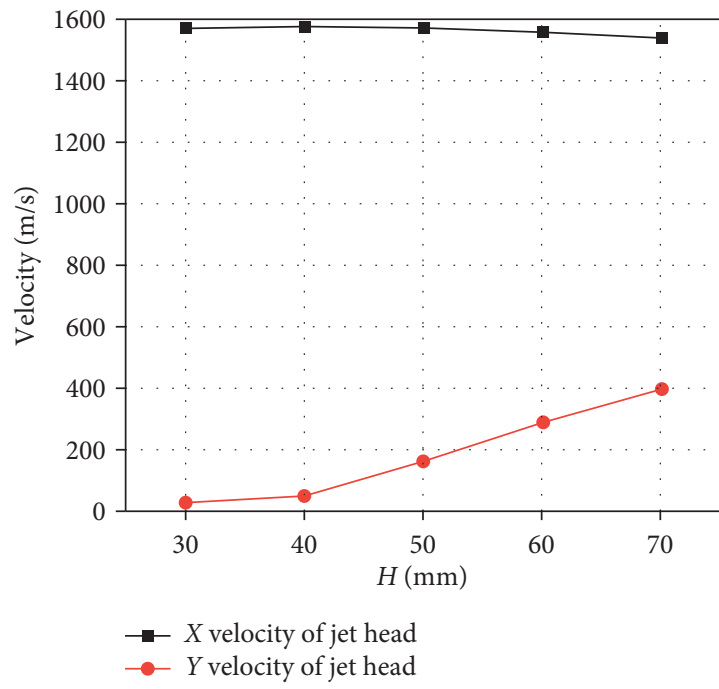

(a)

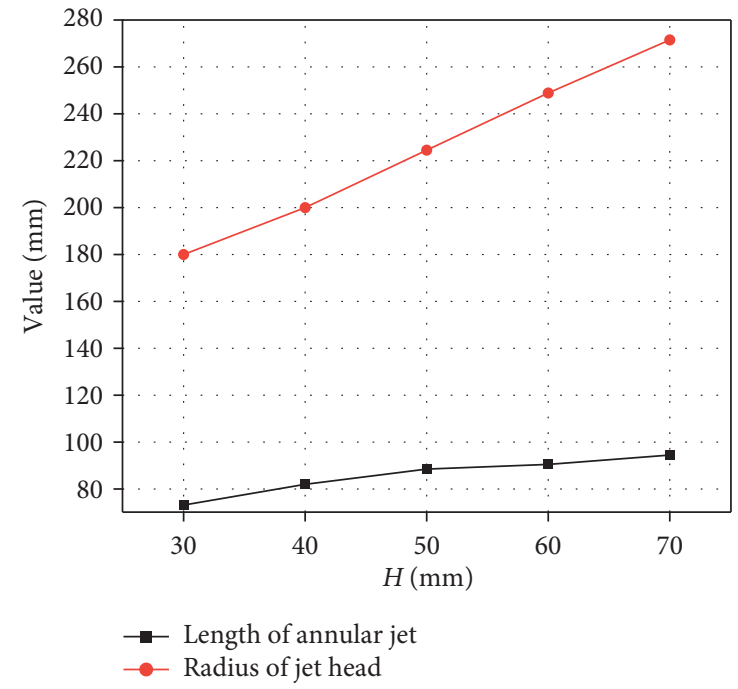

(b)

Figure 10: Influence of factor $H$ on parameters of the annular jet. (a) Profile of the tip velocity of the annular jet at different values of $H$. (b) Influence of factor $H$ on the length and radius of the annular jet.

However, with an increase in $H$ (Figure 11), the reverse degree of the annular jet increases, which gradually leads the penetration of the jet into oblique penetration, thereby greatly reduces the penetration ability of the annular jet. Based on the results of the above analysis, we know that the value of $H$ should not be too large.

Next, we studied the influence of the wall thickness on jet formation. Because the wall thickness is different at each part of the liner, we chose to study the thickness of the bottom of the liner $\left(\delta_{1}\right)$. We keep the value of $\left(-\delta_{1}-\delta_{2}\right)$ constant. Five cases of $\delta_{1}$ were considered: $18 \mathrm{~mm}, 20 \mathrm{~mm}, 22 \mathrm{~mm}, 24 \mathrm{~mm}$, and $26 \mathrm{~mm}$. The influence of $\delta_{1}$ on the annular jet parameters is shown in Figure 12; because of the bending phenomenon in the forming process of the annular jet, the definition of $r_{h}$ has a problem, and we do not record its value. Figure 13 shows the form of the jet at $200 \mu$ s with different $\delta_{1}$ values.

Figure 12 shows that, with an increase in $\delta_{1}$, the value of $V_{t Y}$ remains almost unchanged; however, the values of $V_{t X}$ and $L$ decrease sharply. This means that the penetration ability of the annular jet is reduced. As shown in Figure 13, the middle of the jet gradually protrudes with the increase in $\delta_{1}$, and finally, the jet is bent, which is obviously unfavorable. Therefore, the thickness of the liner should not be too large. However, when $\delta_{1}=18 \mathrm{~mm}$, the jet is damaged. In summary, when the liner is too thick, the jet will be bent, and the penetration ability of the annular jet will be reduced; when the liner is too thin, the jet may fracture in the middle. The thickness of the liner should neither be too thick nor too thin.

3.5. Experimental Verification and Discussion. To verify the penetration capability of the annular-shaped charge, we conducted an experiment wherein an annular-shaped charge penetrated a typical underwater target; the blasting height was set as $300 \mathrm{~mm}$. The charge diameter was $300 \mathrm{~mm}$, the diameter of the inner charge was $100 \mathrm{~mm}$, and the thickness of the wave shaper was $20 \mathrm{~mm}$. The structural parameters of the liners are shown in Figure 14. The target comprised two steel plates and a layer of water sandwiched between them. The plate near the shaped charge is called the front plate, and 


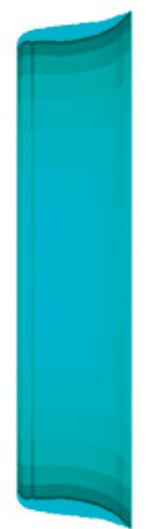

(a)

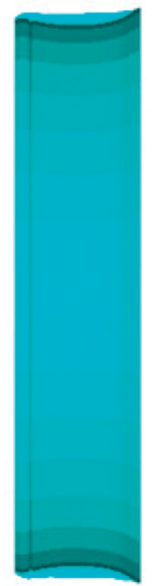

(b)

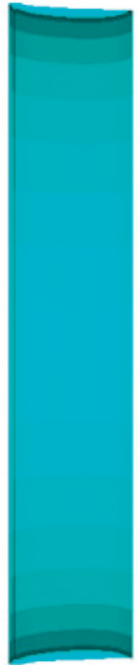

(c)

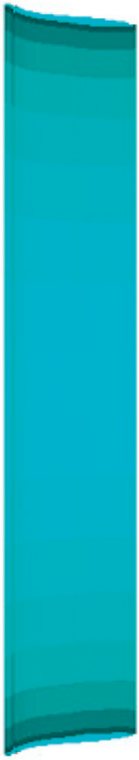

(d)

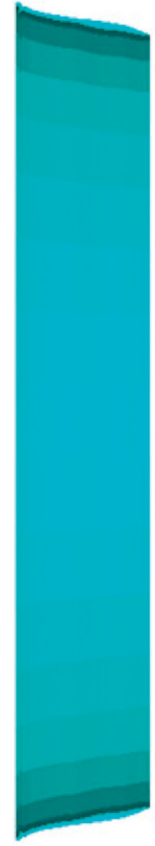

(e)

Figure 11: Shape of the annular jet at $200 \mu \mathrm{s}$ with different values of $H$. (a) $H=30 \mathrm{~mm}$. (b) $H=40 \mathrm{~mm}$. (c) $H=50 \mathrm{~mm}$. (d) $H=60 \mathrm{~mm}$. (e) $H=70 \mathrm{~mm}$.

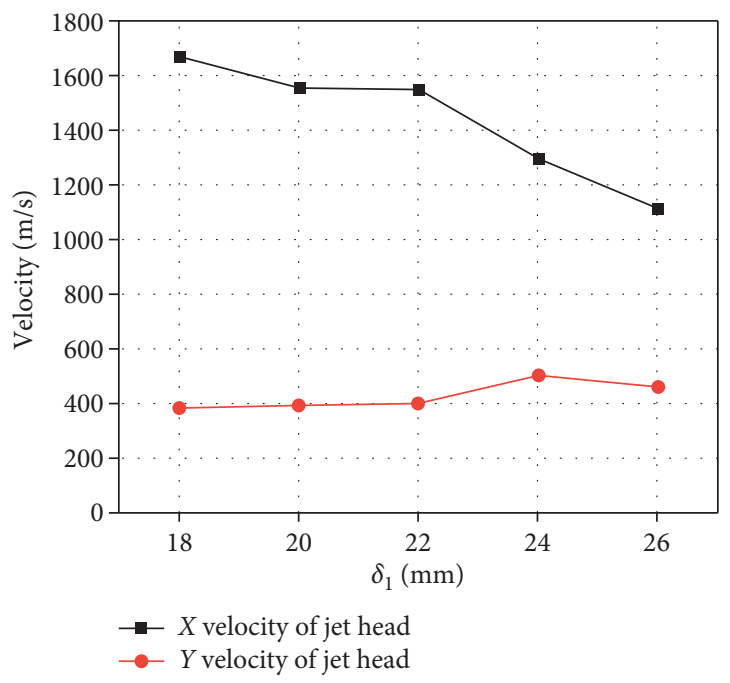

(a)

(b)

Figure 12: Influence of factor $\delta_{1}$ on parameters of the annular jet. (a) Profile of tip velocity of the annular jet at different values of $\delta_{1}$. (b) Influence of factor $H$ on the length of the annular jet.

the other plate is called the back plate. Both steel plates were $50 \mathrm{~mm}$ thick, and the width of the water was $1 \mathrm{~m}$. To reduce the effect of the detonation wave reflected by the ground on jet formation, the charge axis was set at a height of $1.5 \mathrm{~m}$ above the ground; a $1 \mathrm{~m}$-deep pit was dug on the ground at the location of the charge. The experimental layout is shown in Figure 15.

Before the experiment, we first conducted a numerical simulation on the process of jet penetration into the target, and the numerical model is shown in Figure 16. We obtained the forms of the annular jet and JPC during the formation process. With Autodyn's "REMAP"function, we imported the results directly into the penetration model, and this greatly improved the computational efficiency. In particular, to study the damage effect of JPC on the back target, we recorded the change process of the penetration depth and aperture during jet penetration, as shown in Figure 17. The experimental results and the 


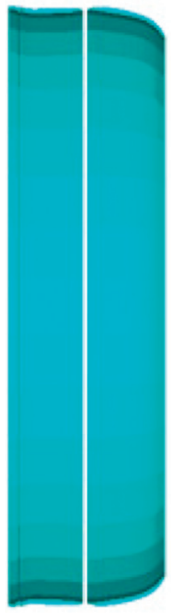

(a)

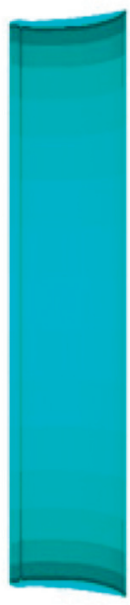

(b)

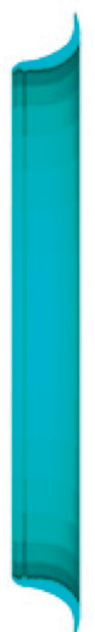

(c)

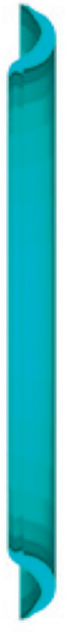

(d)

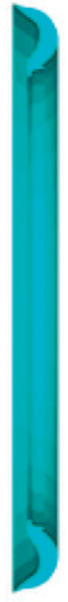

(e)

FIGURE 13: Shape of annular jet at $200 \mu \mathrm{s}$ with different values of $\delta_{1}$. (a) $\delta_{1}=18 \mathrm{~mm}$. (b) $\delta_{1}=20 \mathrm{~mm}$. (c) $\delta_{1}=22 \mathrm{~mm}$. (d) $\delta_{1}=24 \mathrm{~mm}$. (e) $\delta_{1}=26 \mathrm{~mm}$.

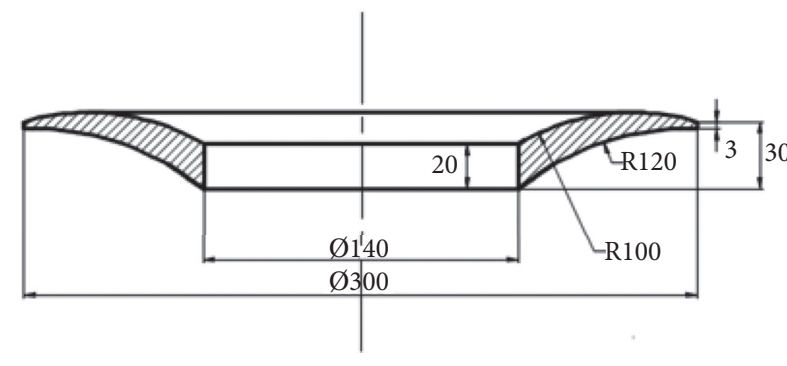

(a)

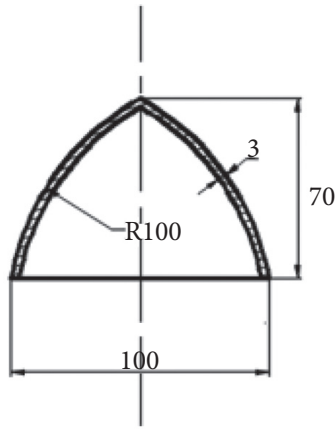

(b)

FIGURE 14: Structural parameters of liners. (a) Annular liner. (b) Eccentric subhemisphere liner.

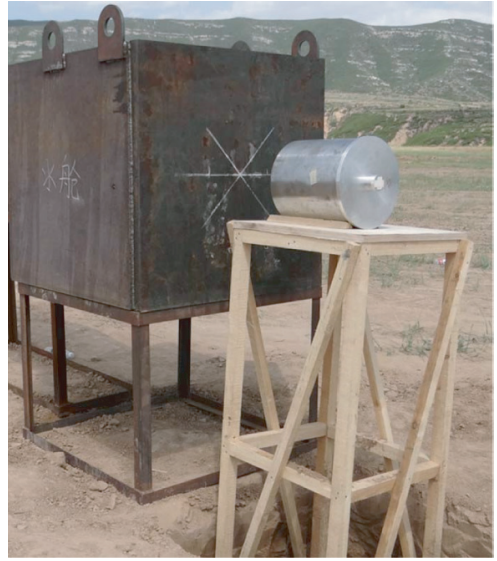

(a)

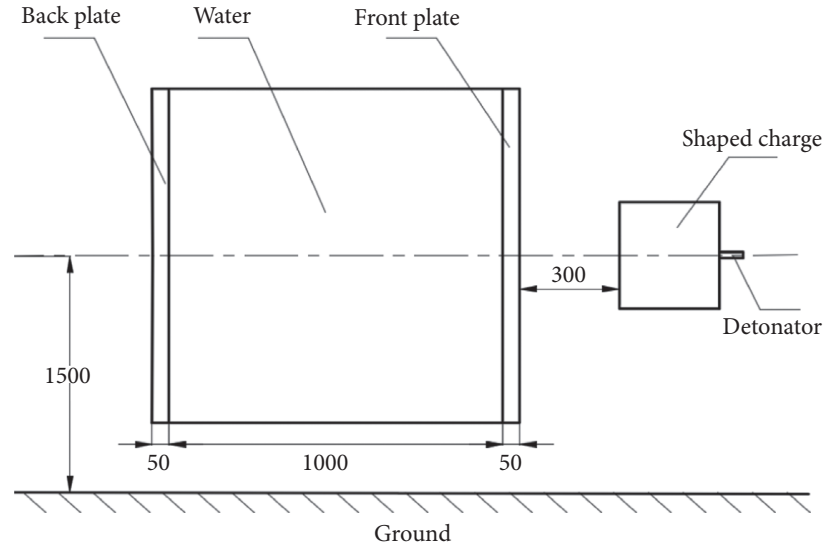

(b)

Figure 15: Penetrating experiment of the annular-shaped charge on a typical underwater target. 


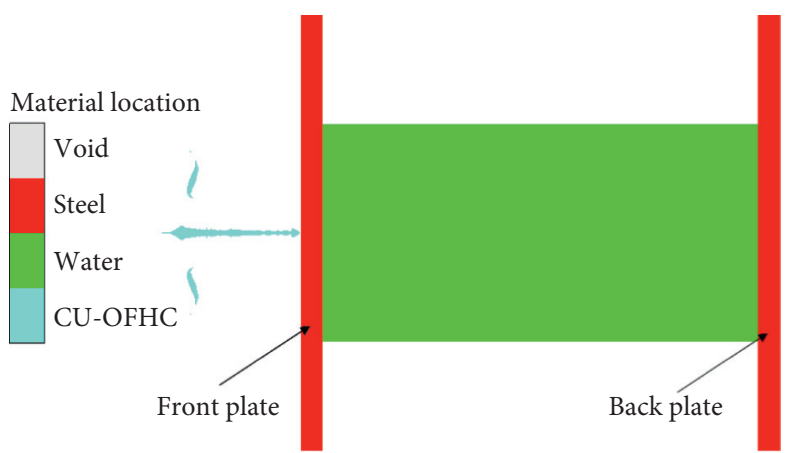

FIGURE 16: Simulation model for the penetration of the annular jet and JPC.

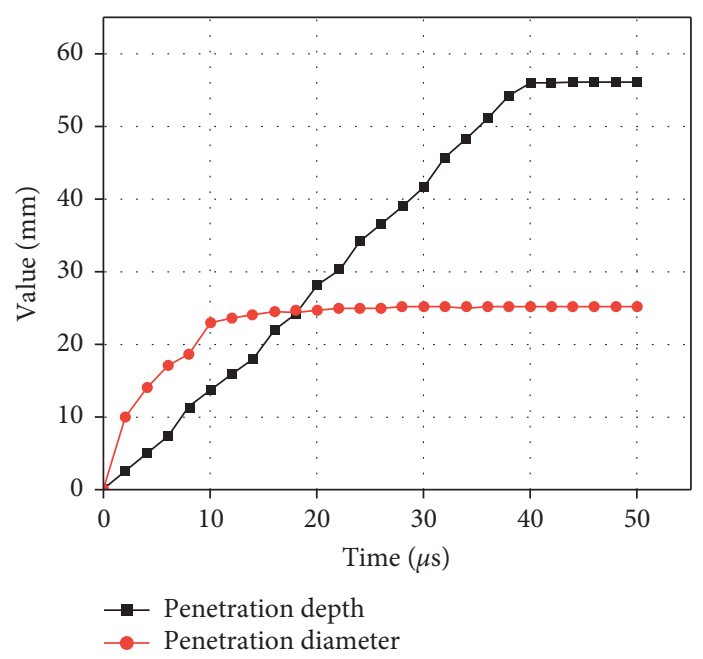

Figure 17: Evolutions of the penetration depth and diameter of the JPC with time.
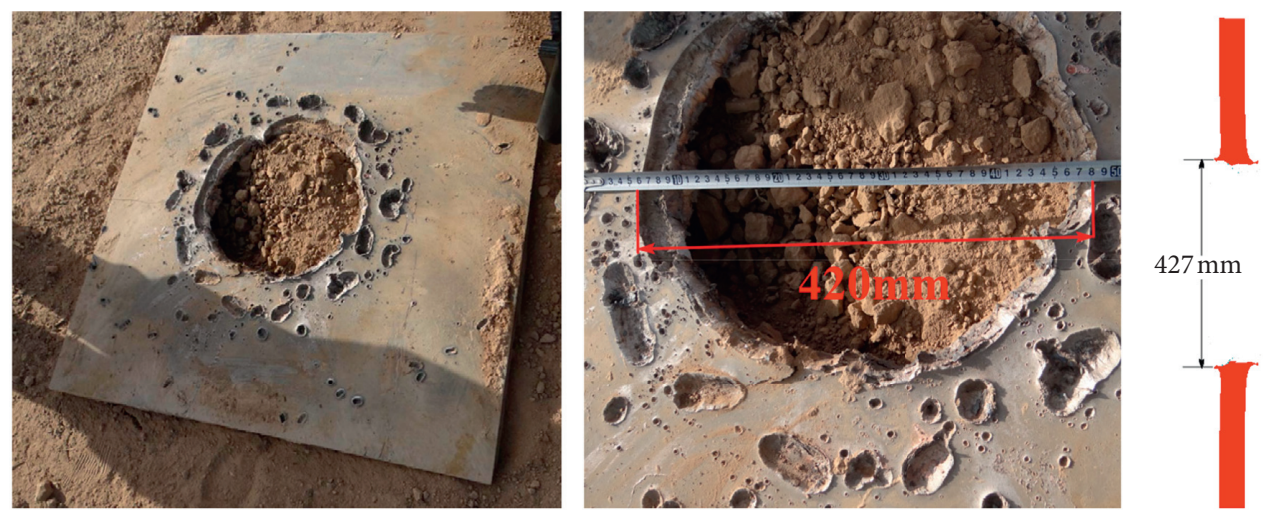

(a)

Figure 18: Continued. 

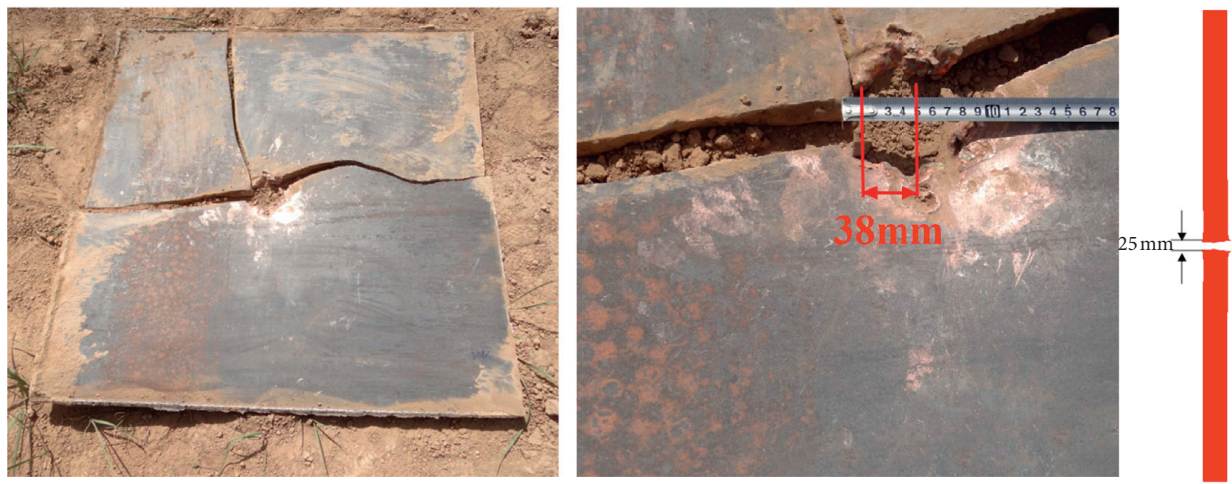

(b)

FIgURE 18: Comparison of experimental and numerical simulation results. (a) Front plate. (b) Back plate.

comparison with the numerical simulation results are illustrated in Figure 18.

Figure 17 shows that the deflections of the back plate are very small during the penetration process because the target plate is relatively thick. The hole diameter increased significantly after the JPC began to penetrate the plates. Here, we define the time at which the JPC contacts the back plate at time 0 . After $10 \mu \mathrm{s}$, the penetration diameter grew slowly, and it finally reached $25 \mathrm{~mm}$ at $20 \mu \mathrm{s}$. The penetration depth of the JPC increased almost linearly over time, and the remaining tip velocity of the JPC was still sufficiently large to penetrate the $50 \mathrm{~mm}$-thick target plate. The JPC takes approximately $40 \mu$ s to penetrate the back plate, and the average velocity of the penetration is $1402.5 \mathrm{~m} / \mathrm{s}$. A penetration depth of more than $50 \mathrm{~mm}$ in the figure is caused by the deformation of the plate under the action of the JPC.

Figure 18 shows that this shaped charge structure can penetrate two plates and the layer of water. The annular jet can create a large hole on the steel plate with the thickness of $50 \mathrm{~mm}$. The penetrating diameter obtained via the experiment is $420 \mathrm{~mm}$, which is 1.4 times of the charge diameter (1.4D). Compared with the penetrating diameter of $427 \mathrm{~mm}$ obtained via the numerical simulation (a deviation of $1.67 \%$ ), we can say that the experimental results properly fit the numerical simulation.

In the experiment, the opening diameter of the JPC on the back plate is $38 \mathrm{~mm}$; however, this value in the simulation is only $25 \mathrm{~mm}$, and it is a deviation of $34.21 \%$. Figure 14(b) shows that the back plate ruptures into three parts in the experiment because the space of the water tank is airtight, and after the jet penetrated the water, the detonation wave and products entered the water tank causing the pressure of water inside to rise sharply; although there was an air vent above the water tank, the pressure generated inside the tank was very high. When the JPC started to penetrate the back plate, the large pressure was applied to the opening, and this caused the back plate to rupture, which increased the opening diameter. However, in the simulation, we set an outflow boundary for the water, and the large generated pressure is ignored; therefore, there is a deviation between the simulation and experimental results.

\section{Conclusions}

In this study, we designed an annular-shaped charge to improve the damage effects of the shaped charge on typical underwater targets. The formation process was analyzed through numerical simulation. Two parameters, $H$ and $\delta_{1}$, were investigated using numerical methods, and their impact on the annular jet formation was analyzed. Finally, the penetration capability of this charge was validated through a penetrating experiment. The main findings are summarized as follows:

(1) This annular-shaped charge forms two separate penetrators: the JPC in the middle and the annular jet outside. Through theoretical analysis and numerical simulation, we found that the annular jet expanded outward during the formation process. At $150 \mu$ s, the tip velocity of the JPC was $6288 \mathrm{~m} / \mathrm{s}$, and the velocity of the annular jet head was $1661 \mathrm{~m} / \mathrm{s}$.

(2) Linear parameters $H$ and $\delta_{1}$ influence the formation of the annular jet. With an increase in $H$, the radius of the jet head $\left(r_{h}\right)$ and length of the jet $(L)$ both increased; however, the $Y$ velocity of the jet head $\left(V_{t Y}\right)$ also increased, which was not beneficial for jet penetration. With an increase in $\delta_{1}$, the jet was bent, which reduced the penetration ability of the annular jet. When the value of $\delta_{1}$ was too small, the jet fractured in the middle. Therefore, we found that the liner should neither be too thick nor too thin.

(3) The annular-shaped charge can penetrate the underwater target and create a large opening on the target. The penetrating diameter on the front plate was $420 \mathrm{~mm}$, which is 1.4 times of the charge diameter. There was a $1.67 \%$ deviation compared with the penetrating diameter $(427 \mathrm{~mm})$ obtained via the numerical simulation.

\section{Data Availability}

The data used to support the findings of this study are available from the corresponding author upon reasonable request. 


\section{Conflicts of Interest}

The authors declare that they have no conflicts of interest.

\section{Acknowledgments}

This work was financially supported by the China Postdoctoral Science Foundation (Grant no. 2019M661070) and the Fund Project of Science and Technology on Transient Impact Laboratory (Grant no. 6142606191105). The financial contributions are gratefully acknowledged.

\section{References}

[1] Z. Zhang, L. Wang, F. Ming, V. V. Silberschmidt, and H. Chen, "Application of smoothed particle hydrodynamics in analysis of shaped-charge jet penetration caused by underwater explosion," Ocean Engineering, vol. 145, pp. 177-187, 2017.

[2] Y. Chen, X. Yao, and X. Cui, "A numerical and experimental study of wall pressure caused by an underwater explosion bubble," Mathematical Problems in Engineering, vol. 2018, Article ID 6139510, 10 pages, 2018.

[3] J. Ning, C. Wang, and T. Ma, "Numerical analysis of the shaped charged jet with large cone angle," International Journal of Impact Engineering, vol. 7, pp. 71-78, 2006.

[4] M. Johnston and S. Lim, "Numerical observation of the jet flight patterns of linear shaped charges," Applied Sciences, vol. 2, no. 3, pp. 629-640, 2012.

[5] J. Xiao, X. Zhang, Y. Wang, F. Xu, and H. Wang, "Demolition mechanism and behavior of shaped charge with reactive liner," Propellants, Explosives, Pyrotechnics, vol. 41, no. 4, pp. 612-617, 2016.

[6] D. Cardoso and F. Teixeira-Dias, "Modelling the formation of explosively formed projectiles (EFP)," International Journal of Impact Engineering, vol. 93, pp. 116-127, 2016.

[7] Q. Q. Xiao, Z. X. Huang, X. Jia, X. D. Zu, and Q. F. Zhu, "Shaped charge penetrator into soil-concrete double-layered target," International Journal of Impact Engineering, vol. 109, pp. 302-310, 2017.

[8] X. Cheng, G. Huang, and C. Liu, "Design of a novel linear shaped charge and factors influencing its penetration performance,” Applied Sciences-Basel, vol. 8, p. 1863, 2018.

[9] J. Yi, Z. Wang, and J. Yin, "Simulation study on expansive jet formation characteristics of polymer liner," Materials, vol. 12, no. 5, p. 744, 2019.

[10] S. Zaki, E. Uddin, B. Rashid, A. Mubashar, and S. R. Shah, "Effect of liner material and explosive type on penetration effectiveness of shaped charge," Proceedings of the Institution of Mechanical Engineers, Part L: Journal of Materials: Design and Applications, vol. 233, no. 7, pp. 1375-1383, 2019.

[11] O. V. Svirsky and M. A. Vlasova, "On the penetration capability of shaped charges with conical and hemispherical liners," Combustion, Explosion, and Shock Waves, vol. 55, no. 6, pp. 739-743, 2019.

[12] D. Pyka, A. Kurzawa, and M. Bocian, "Numerical and experimental studies of the LK type shaped charge," Applied Sciences-Basel, vol. 10, p. 6742, 2020.

[13] Z. Zhang, L. Sun, X. Yao, and X. Cao, "Smoothed particle hydrodynamics simulation of the submarine structure subjected to a contact underwater explosion," Combustion, Explosion, and Shock Waves, vol. 51, no. 4, pp. 502-510, 2015.

[14] A. S. Kumar, K. U. Gokul, and P. V. K. Rao, "Blast loading of underwater targets-a study through explosion bulge test experiments," International Journal of Impact Engineering, vol. 76, pp. 189-195, 2015.

[15] Z. Zhang, L. Wang, and V. V. Silberschmidt, "Damage response of steel plate to underwater explosion: effect of shaped charge liner," International Journal of Impact Engineering, vol. 103, pp. 38-49, 2017.

[16] D. J. Leidel, "A design study of an annular-jet charge for explosive cutting," Ph. D Thesis, Drexel University, Philadelphia, PA, USA, 1978.

[17] M. C. Chick, T. C. Bussell, and C. P. Lam, "Development of a cookie-cutter explosively formed projectile," in Proceedings of the 1998 17th International Symposium on Ballistics, pp. 167-174, Midrand, South Africa, March 1998.

[18] P. Konig and F. Monster, "The design and performance of annular EFP's," in Proceedings of the 2001 19th International Symposium on Ballistics, pp. 749-754, Interlaken, Switzerland, May 2001.

[19] C. Wang, F. Huang, and J. Ning, "Jet formation and penetration mechanism of W typed shaped charge," Acta Mechanica Sinica, vol. 25, no. 1, pp. 107-120, 2009.

[20] F. J. Meister and F. Haller, "Experimental and numerical studies of annular projectile charges," in Proceedings of the 19th International Symposium on Ballistics, pp. 575-581, Interlaken, Switzerland, May 2001.

[21] F. Richard, T. LaMar, and N. William, "Toroidal warhead development," in Proceedings of the 2010 25th International Symposium on Ballistics, pp. 861-865, Beijing, China, May 2010.

[22] Y. Li, Y. Huang, Y. Zhang et al., "Numerical simulation of double explosively formed ring warhead," in Proceedings of the 2010 25th International Symposium on Ballistics, pp. 837-844, Beijing, China, May 2010.

[23] W. Xu, C. Wang, and D. Chen, "Formation of a bore-center annular shaped charge and its penetration into steel targets," International Journal of Impact Engineering, vol. 127, pp. 122-134, 2019.

[24] W.-L. Xu, C. Wang, J.-M. Yuan, and T. Deng, "Bore-center annular shaped charges with different liner materials penetrating into steel targets," Defence Technology, vol. 15, no. 5, pp. 796-801, 2019.

[25] X. Zu, Z. Huang, and C. Zhu, "Study of detonation wave contours in EFP warhead," Defence Technology, vol. 12, pp. 129-133, 2016.

[26] Y. Liu, J. Yin, and Z. Wang, "Study on the overdriven detonation wave propagation in double-layer shaped charge," Physics of Fluids, vol. 31, 2019.

[27] ANSYS Inc, AUTODYN Material Library, ANSYS Inc., Canonsburg, PA, USA, 2016. 